\title{
Assessing Hydrological Impacts of Climate Change: Modeling Techniques and Challenges
}

\author{
Subimal Ghosh ${ }^{1, *}$ and Chaitali Misra ${ }^{2}$ \\ ${ }^{I}$ Department of Civil Engineering,Indian Institute of Technology Bombay, Powai, Mumbai - 400076, India \\ ${ }^{2}$ Halliburton Technology Centre, Pune, India
}

\begin{abstract}
Climate Change refers to any systematic change in the long-term statistics of climate elements (such as temperature, pressure, or winds) sustained over several decades or longer time periods. General Circulation Models (GCMs) are tools designed to simulate time series of climate variables globally, accounting for effects of greenhouse gases in the atmosphere and resulting global climate change. They are currently the most credible tools available for simulating the response of the global climate system to increasing greenhouse gas concentrations, and to provide estimates of climate variables (e.g. air temperature, precipitation, wind speed, pressure etc.) on a global scale. GCMs demonstrate a significant skill at the continental and hemispheric spatial scales and incorporate a large proportion of the complexity of the global system; they are, however, inherently unable to represent local subgrid-scale features and dynamics. The spatial scale on which a GCM can operate (e.g., $3.75^{\circ}$ longitude X $3.75^{\circ}$ latitude for Coupled Global Climate Model, CGCM2) is very coarse compared to that of a hydrologic process (e.g., precipitation in a region, streamflow in a river etc.) of interest in the climate change impact assessment studies. Moreover, accuracy of GCMs, in general, decreases from climate related variables, such as wind, temperature, humidity and air pressure to hydrologic variables such as precipitation, evapotranspiration, runoff and soil moisture, which are also simulated by GCMs. These limitations of the GCMs restrict the direct use of their output in hydrology. Hydrologic implications of global climate change are usually assessed by downscaling appropriate predictors simulated by General Circulation Models (GCMs). Conventionally rainfall is first downscaled with dynamic or statistical downscaling and then the predicted rainfall is used in hydrologic models to forecast hydrologic scenarios of future.
\end{abstract}

\begin{abstract}
Although this methodology is widely practiced, there are some limitations: (a) uncertainty resulting from the use of multiple GCMs, scenarios, downscaling models is seldom considered; (b) local changes (e.g., urbanization, population growth, deforestation) which affect directly the hydrology of a region are considered in a very limited number of studies. The present paper focuses on these limitations and proposes different approaches to deal with the problems.
\end{abstract}

Key Words: Climate Change, Downscaling, River Basin Scale Hydrology.

\section{INTRODUCTION}

Climate change refers to any systematic change in the long-term statistics of climate elements (such as temperature, pressure, or winds) sustained over several decades or longer time periods (American Meteorological Society, http://amsglossary.allenpress.com/glossary). Observations that delineate how global temperature has increased in the past, show (Fig. 1) that the global average surface temperature has increased by $0.74^{\circ} \mathrm{C} /$ Century [1]. It is observed that in the $20^{\text {th }}$ century, 1990s was the warmest decade and 1998 was the warmest year [2]. One of the major causes of global warming is the emission of greenhouse gases due to anthropogenic activities [2]. The consequences of global warming are reflected in global as well as regional climate in terms of changes in key climatic variables such as precipitation and atmospheric moisture, snow cover, extent of land and sea ice, sea level and patterns in atmospheric and oceanic circu-

*Address correspondence to this author at the Department of Civil Engineering,Indian Institute of Technology Bombay, Powai, Mumbai - 400076, India; Tel: +91 222576 7319; Fax: +91 222576 7302;

E-mail: subimal@civil.iitb.ac.in lation. IPCC [2] lists out following evidences of climate change. There are evidences of changes in precipitation in the middle and high latitudes of the Northern Hemisphere. Based on tide gauge data, the rate of global mean sea level rise during the $20^{\text {th }}$ century is estimated to be in the range of 1.0 to $2.0 \mathrm{~mm} / \mathrm{yr}$, with a central value of $1.5 \mathrm{~mm} / \mathrm{yr}$. Decreasing snow cover and land-ice extent continue to be positively correlated with increasing land-surface temperatures. Satellite data show that it is very likely that there have been decreases of about $10 \%$ in the extent of snow cover since the late 1960s. The behaviour of El Nino Southern Oscillation (ENSO) has been unusual since the mid-1970s compared with the previous 100 years, with warm phase ENSO episodes being relatively more frequent, persistent, and intense than the opposite cool phase. This recent behaviour of ENSO is reflected in variations in precipitation and temperature over much of the global tropics and sub-tropics. As summarized above, there exists a significant evidence of climate change, particularly over the recent decades.

Water resources are inextricably linked with climate, so the prospect of global climate change has serious implications for water resources and regional development [2]. It is mentioned in the IPCC report [2] that increased evaporation 


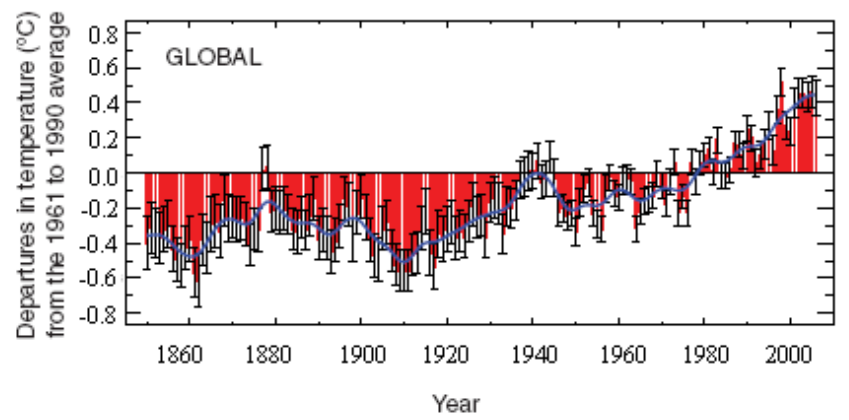

Fig. (1). Global Temperature Trend (IPCC, 2007).

(resulting from higher temperatures), combined with regional changes in precipitation characteristics (e.g., total amount, variability, and frequency of extremes), has the potential to affect mean runoff, frequency and intensity of floods and droughts, ground water, soil moisture, and water supplies for irrigation and hydroelectric generation.

Assessing the impact of climate change on hydrology essentially involves projections of climatic variables (e.g., temperature, humidity, mean sea level pressure etc.) at a global scale, downscaling of global scale climatic variables into local scale hydrologic variables and computations of risk of hydrologic extremes in future for water resources planning and management. Projections of climatic variables globally can be performed with General Circulations Models (GCMs), which, are currently the most credible tools available for simulating the response of the global climate system to increasing greenhouse gas concentrations, and to provide estimates of climate variables (e.g. air temperature, precipitation, wind speed, pressure etc.) on a global scale. GCMs are able to simulate reliably the most important mean features of the global climate at planetary scales. However, at finer spatial resolutions GCMs have much lower skill. The spatial scale on which a GCM can operate (e.g. $3.75^{\circ}$ longitude X $3.75^{\circ}$ latitude for Coupled Global Climate Model, CGCM2) is very coarse compared to that of a hydrologic process (e.g., precipitation in a region, streamflow in a river basin etc.) to be modelled in the climate change impact assessment studies. Downscaling, in the context of hydrology, is a method to predict the hydrologic variables (e.g., rainfall and streamflow) at a smaller scale based on large scale climatological variables (e.g., mean sea level pressure) simulated by a GCM. The next section presents overview of different downscaling techniques.

\section{DOWNSCALING TECHNIQUES}

Downscaling techniques can be broadly classified into dynamic and statistical downscaling (Table 1). Poor performances of GCMs at local and regional scales have lead to the development of Limited Area Models (LAMs) in which a fine computational grid over a limited domain is nested within the coarse grid of a GCM [3]. This procedure is also known as dynamic downscaling. A major drawback of dynamic downscaling which restricts its use in climate change impact studies, is its complicated design and high computational cost. Moreover, dynamic downscaling is inflexible in the sense that expanding the region or moving to a slightly different region requires redoing the entire experiment [4].
Another approach to dynamic downscaling is statistical downscaling, in which, regional or local information about a hydrologic variable is derived by first determining a statistical model which relates large scale climate variables (or predictors) to regional or local scale hydrologic variables (or predictands). Then the large scale output of a GCM simulation is fed into this statistical model to estimate the corresponding local or regional hydrologic characteristics [5]. There are three implicit assumptions involved in statistical downscaling [6]: firstly, the predictors are variables of relevance and are realistically modeled by the GCM; secondly, the empirical relationship is valid also under altered climatic conditions, and thirdly, the predictors employed fully represent the climate change signal. Statistical downscaling methods can be further classified into weather generators, weather typing and transfer functions based on the use of different statistical tools.

Weather generators are statistical models of sequences of weather variables. They can also be regarded as complex number generators, the output of which resembles daily weather data at a particular location. There are two fundamental types of daily weather generators, based on the approach to model daily precipitation occurrence: the Markov chain approach [7] and the spell-length approach [8]. In the Markov chain approach, a random process is constructed which determines a day at a station as rainy or dry, conditional upon the state of the previous day, following given probabilities. In case of spell-length approach, instead of simulating rainfall occurrences day by day, spell-length models operate by fitting probability distribution to observed relative frequencies of wet and dry spell lengths. In either case, the statistical parameters extracted from observed data are used along with some random components to generate a similar time series of any length. In statistical downscaling, the parameters of the weather generators are conditioned upon a large-scale state, or the relationships between daily weather generator parameters and climatic averages can be used to characterize the nature of future days statistics on the basis of more readily available time-averaged climate change information [9]. Weather typing approaches involve grouping local, meteorological variables in relation to different classes of atmospheric circulation. Future regional climate scenarios are constructed, either by resampling from the observed variable distribution (conditional on circulation patterns produced by a GCM), or by first generating synthetic sequences of weather patterns using Monte Carlo techniques and resampling from the generated data. The mean or fre- 


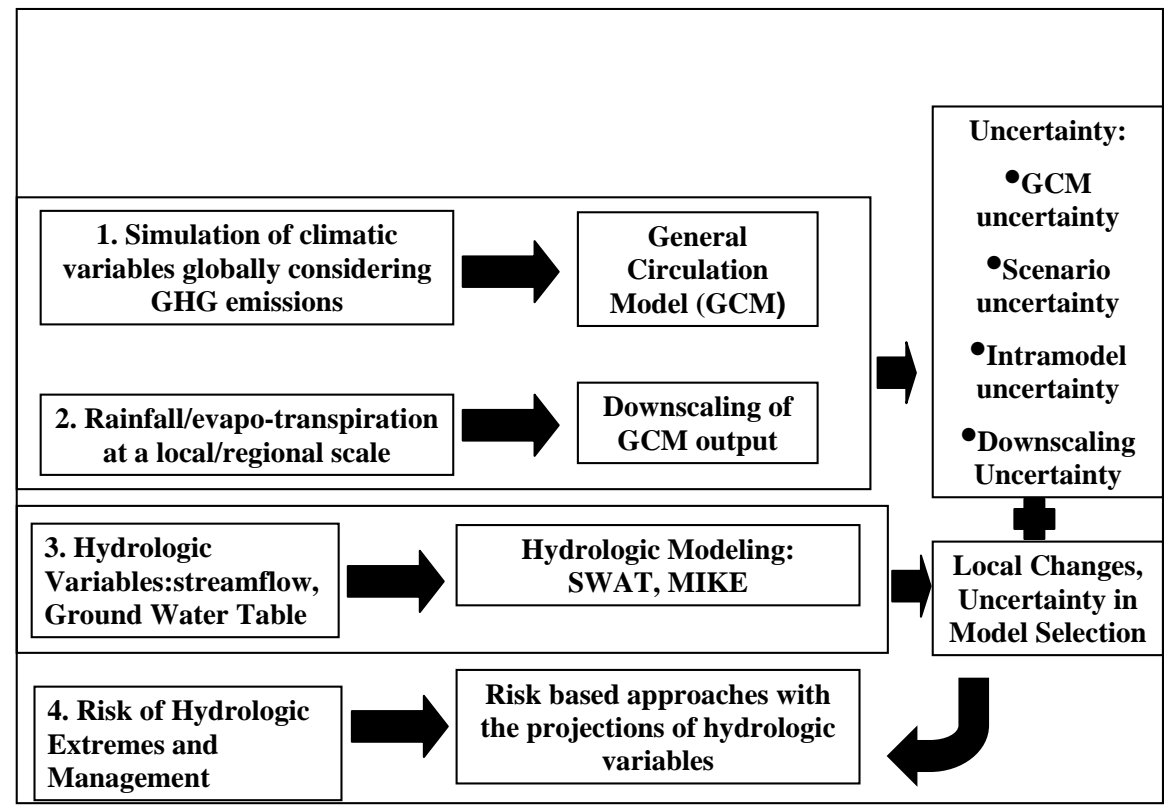

Fig. (2). Flowchart for Climate Change Impacts Assessment on River Basin Scale Hydrology.

quency distribution of the local climate is then derived by weighting the local climate states with the relative frequencies of the weather classes. Climate change is then estimated by determining the change of the frequency of weather classes. The most popular approach of statistical downscaling is the use of transfer function which is a regression based downscaling method that relies on direct quantitative relationship between the local scale climate variable (predictand) and the variables containing the large scale climate information (predictors) through some form of regression. Individual downscaling schemes differ according to the choice of mathematical transfer function, predictor variables or statistical fitting procedure. Todate, linear and non-linear regression [5], Artificial Neural Network (ANN) [4] and canonical correlation [10] have been used to derive predictor-preditand relationship. Among them, ANN-based downscaling techniques have gained wide recognition owing to their ability to capture non-linear relationships between predictors and predictand $[4,6]$.

Despite a number of advantages, the traditional neural network models have several drawbacks including possibility of getting trapped in local minima and subjectivity in the choice of model architecture [11]. Recently, Vapnik [12,13] pioneered the development of a novel machine learning algorithm, called Support Vector Machine (SVM), which provides an elegant solution to these problems. Although, recurrent ANNs perform better than feed forward neural networks in many applications (e.g., [14]), being a subset of neural networks they involve numerical algorithms (back propagation or conjugate gradient) in training which sometimes do not result in global optimum values of the parameters. On the other hand, as SVM involves analytical methods such as quadratic programming it always results in global optima. Secondly ANN trains a model with the objective of empirical risk minimization which lacks in generalization of input output relationship. SVM on the other hand performs structural risk minimization which is more generalized and results in more credible solutions. The SVM has been used in statistical downscaling model by Tripathi et al. [15]. SVM has some drawbacks of rapid increase of basis functions with the size of training data set [16], which may lead to overtraining (large difference between the system performance measure of training and testing data set). This was overcome by Ghosh and Mujumdar [17] using Relevance Vector Machine, which is applied for projection of streamflow of Mahanadi River, India.

To summarize, dynamic downscaling models are based on geophysics, however they are computationally expensive and the methodology changes with change in case study. Statistical downscaling models on the other hand are based on statistical relationship and hence require less computational time. Transfer functions are most popular downscaling model due to their simplicity but can not model very well variability and extreme events. Their performances are poor in simulating daily rainfall but projects well monthly rainfall which are averaged and for such cases the effects of extremes are minimized. Stochastic weather generators are good for modelling daily rainfall but they can model only rainfall state, not the rainfall values. Multisite daily rainfall modelling is still a challenge for researchers working in the field of downscaling.

\section{CLIMATE CHANGE IMPACTS ASSESSMENT ON INDIAN RIVER BASINS}

The steps involved in assessing impacts of climate change on river basin scale hydrology are presented in Fig. (2). They are:

1. Simulation of large scale climate variables by GCMs.

2. Downscaling large scale climate variables to local scale hydro-meteorological variables (e.g., rainfall).

\section{Hydrologic modelling}

4. Analysis of hydrologic extremes.

The first two steps are burdened with a considerable amount of uncertainty, stemming from several sources [18]. For impact estimates based on downscaling of General Circulation Model (GCM) outputs, different levels of uncertainty are related to: (i) GCM uncertainty or intermodel vari- 


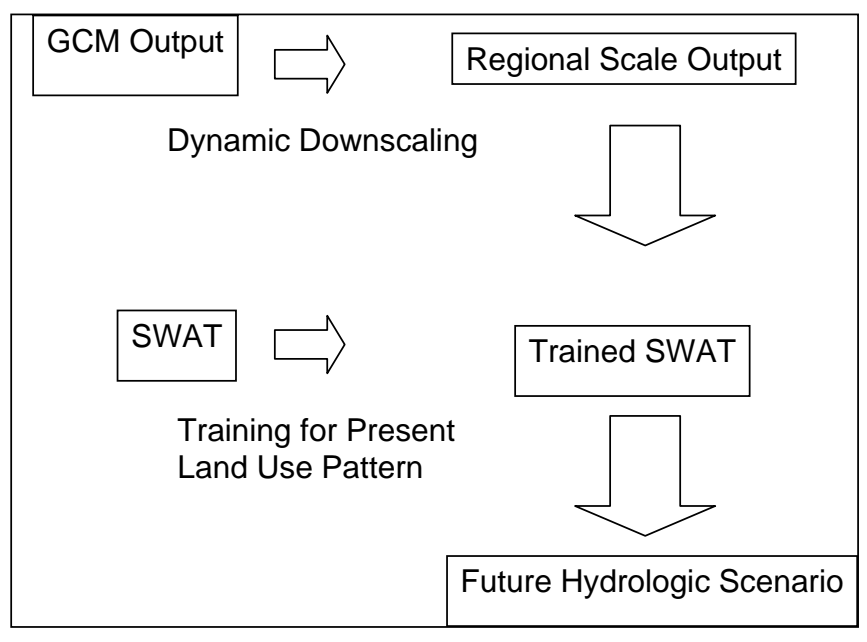

Fig. (3). Dynamic Downscaling Models coupled with SWAT.

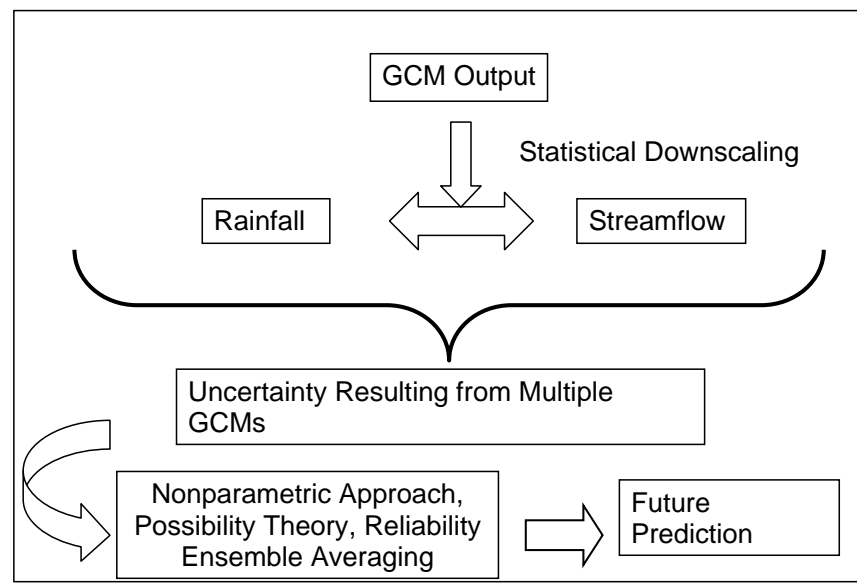

Fig. (4). Statistical downscaling model coupled with uncertainty modeling.

ability (arising from use of different GCMs), (ii) scenario uncertainty or interscenario variability, (iii) different realizations of a given GCM due to parameter uncertainty (intramodel variability) and (iv) uncertainty due to downscaling methods. GCM uncertainty, which is due to incomplete knowledge about the underlying geophysical processes of global change, leads to limitations in the accuracy of the models. Scenario uncertainty results from unpredictability in the forecast of future socio-economic and human behavior resulting in future Green House Gas (GHG) emission scenarios. Downscaled outputs of a single GCM with a single climate change scenario represents a single trajectory among a number of realizations derived using various scenarios with GCMs. Such a single trajectory alone can not represent a future hydrologic scenario, and will not be useful in assessing hydrologic impacts due to climate change. No quantified probability is attached to the simulated outcome of a single GCM for a single scenario and thus the approach of downscaling a single GCM output is not particularly useful for risk adaption studies [19]. Therefore there is a need to model the uncertainties before the use of downscaled output in hydrologic modelling.

A hydrologic model used for estimating the response of rainfall (viz., runoff), needs the land use pattern of the river basin. With the change in time, the land use pattern will change and depends on socio-economic conditions and demographic data. Considering the present land use pattern to be same for future is unrealistic and results in significant error. This input can be considered as local changes and should be considered for hydrologic projections. Furthermore the uncertainty resulting from the use of multiple hydrologic models should also be considered and finally after considering all sorts of uncertainties the risk of hydrologic extremes should be computed.

The methodology adopted for Indian River basin to assess impacts of climate change can be broadly classified into:

1. Dynamic downscaling model coupled with Soil Water Assessment Tool (SWAT).

2. Statistical downscaling model coupled with uncertainty modelling.

\section{Dynamic Downscaling Models Coupled with SWAT}

This model [20] (Fig. 3) includes generation of local meteorological data under GHG conditions and then the use of local scale meteorological data in a hydrologic model (Soil Water Assessment Tool [SWAT]). Dynamic downscaling for local scale meteorological prediction was performed with Hadley Regional Model HadRM2 with a resolution of 0.440 latitude by 0.440 longitude. A hydrologic model SWAT has been trained for river basins and the local predicted meteorological variables are used in trained SWAT for hydrologic scenario prediction. The SWAT model simulates the hydrologic cycle at daily time steps. SWAT is a distributed, continuous, hydrological model with an ArcView GIS interface (AVSWAT). The interface has been used for pre- and postprocessing of the data and outputs. The methodology is applied by Gosain et al. [20] for Krishna and Mahanadi river basin. The limitation of this model are:

1. Single GCM has been considered, however it has been observed that output of one GCM deviates from that of another significantly and therefore over-reliance of a single GCM results in misleading projections.

2. The SWAT model is trained with present land use pattern. It is quite expected that in future the land use pattern will change which definitely has impacts on hydrologic processes. Such land use change has not been considered in Gosain et al. [20].

3. The hydrologic projections under GHG condition have been presented (Gosain et al., 2006) year wise (e.g., for 2041, 2042 etc.), however GCMs fail to model interannual variability. Therefore decade wise/ 30 years wise statistical properties of hydrologic variables are more appropriate mode of predictions.

\section{Statistical Downscaling Model Coupled with Uncertainty Modelling}

The second type of models used for Indian river basins are statistical downscaling methods coupled with uncertainty modeling (Fig. 4). In such framework [21], statistical downscaling model is first developed to predict streamflow directly from large scale climate variables simulated by GCMs [17]. It is assumed that local level changes are actually contributing to global changes which is considered in GCM 


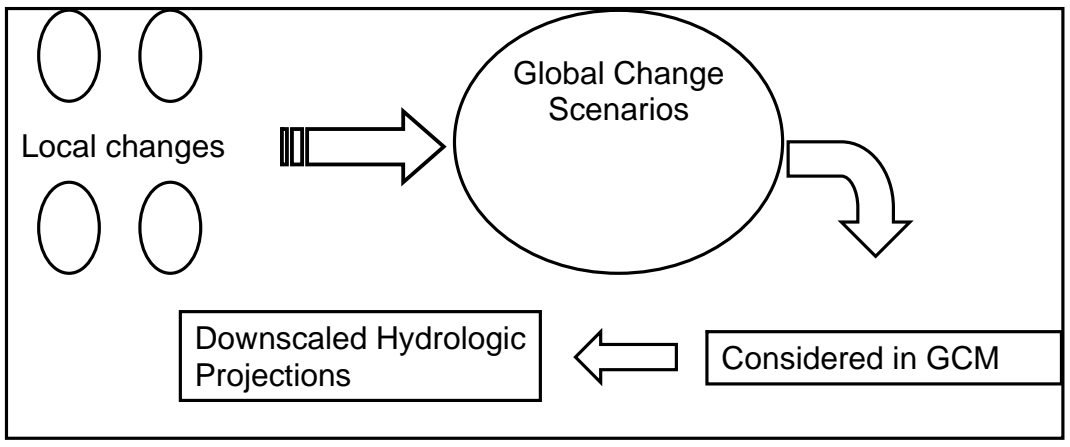

Fig. (5). Assumptions for Statistical Downscaling Models for Streamflow Predictions.

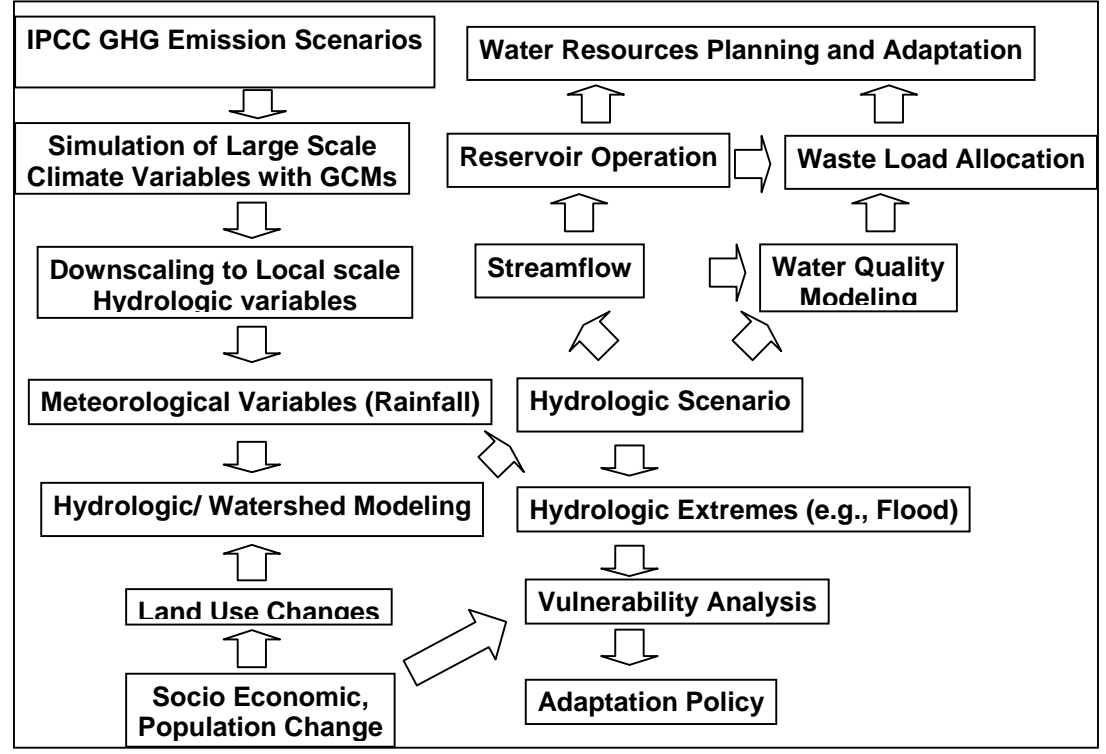

Fig. (6). Integrated Catchment Management under Climate Change.

simulations. Therefore use of GCM simulations for streamflow prediction is actually implicitly considering the local changes (Fig. 5). However, this is a very weak assumption and does not consider the impacts of case study specific local changes.

The model has been applied by Mujumdar and Ghosh [21] for Mhanadi river basin to compute the inflow to Hirakud dam. The Hirakud dam is located on the Mahanadi river in Orissa State of India. The monthly streamflow at Hirakud dam, for the period 1961 to 2005, is obtained from the Department of Irrigation, Government of Orissa, India. A subset of the data set, viz., streamflow data from 1961 to 1990 is used for statistical downscaling and the rest of the data is used for modeling GCM and scenario uncertainty (with Third Assessment Report [TAR] projections) with possibility distribution.

Following IPCC story-lines and Third Assessment Report [TAR], it is argued in the possibilistic approach [21], that the signals of climate forcing would be visible after the year 1990. For appropriate planning and adaptation responses, with the passage of time, it is relevant to assess the effectiveness of GCMs in modelling climate change and also to judge which of the scenarios represent the present situation best under climate forcing. A methodology based on possibility distribution has been developed by Mujumdar and Ghosh [21] to model GCM and scenario uncertainty with an objective of assignment of possibility values to GCMs and scenarios depending on their performance in modeling signals of climate forcing in the recent past (years 1991-2005). The possibilities thus obtained are used as weights in deriving the possibilistic mean CDF (weighted CDF) for standard time slices of 2020s, 2050s, and 2080s.

The limitations of this model are:

1. The assumption for local changes is very weak and does not consider case study specific local changes. It has been shown by Ghosh et al. [22] that, local changes have significant impacts on local scale hydrologic variables.

2. Weights are assigned to the GCMs based on past performance. As GCM parameterization is performed based on past data, significant difference between the GCMs may not be observed for past data. Therefore all the GCMs get similar weights. The future performance of GCMs based on "model convergence" for future should be considerd in assigning weights to GCMs. This has been experimented by Ghosh and Mujumdar [23].

Therefore the models developed for Indian river basins can not be considered as a robust and complete models and need lot of improvements. The steps, which should be used for developing integrated catchments management under climate change are the followings (Fig. 6): 


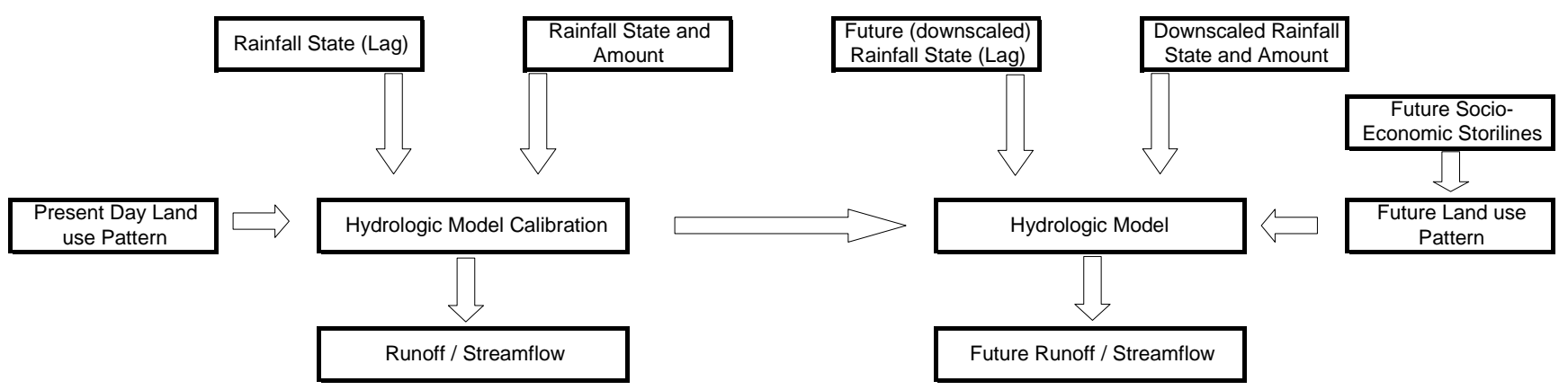

Fig. (7). Flowchart for Hydrologic Modeling.

Table 1. Comparison of Downscaling Techniques

\begin{tabular}{|c|c|c|c|}
\hline \multicolumn{2}{|c|}{ Downscaling Techniques } & Advantages & Limitations \\
\hline \multicolumn{2}{|c|}{ Dynamic } & Physics based model & Computationally expensive \\
\hline \multirow{3}{*}{ Statistical Downscaling } & $\begin{array}{l}\text { Stochastic weather } \\
\text { generator }\end{array}$ & $\begin{array}{c}\text { Model very well rainfall state of a particular day } \\
\text { Computationally not expensive }\end{array}$ & Can not predict rainfall values \\
\hline & Weather Typing & Computationally inexpensive & $\begin{array}{l}\text { May not simulate rainfall correctly always and } \\
\text { less popular }\end{array}$ \\
\hline & Transfer function & Simple and computationally inexpensive & $\begin{array}{c}\text { Can model extreme rainfall. } \\
\text { Can not model daily rainfall well }\end{array}$ \\
\hline
\end{tabular}

Step 1- The first step is to downscale (dynamically or statistically) large scale climate variables (Mean Sea Level Pressure (MSLP), temperature, wind velocity etc.) simulated by General Circulation Model (GCM) to rainfall. For prediction of multi-site rainfall in a river basin, correlation between the rainfalls of multiple sites is often not captured by conventional statistical downscaling technique. Furthermore these methods fail to model the variability of the predictand (hydrologic variable). Improvements are required in statistical techniques used for statistical downscaling and modeling the extreme events. Further emphasis should be given in uncertainty modelling and over-reliance of single GCM is misleading. Weights can be assigned to GCMs based on model performance (for observed period) and model convergence (future). Details of the uncertainty modelling may be found in Ghosh and Mujumdar [23].

Step 2- The second step is to generate local scale scenarios. The methodology may be developed based on the followings:

1. Remote sensing images of river basins to generate land use/cover, digital elevation model, land surface temperature, soil moisture etc. for the last few decades.

2. Identification of local changes like urbanization, water bodies, cropping pattern, meteorological changes, $\mathrm{CO}_{2}$ concentration, population, deforestation etc.

3. Collection of census data

4. Prediction of future local scenarios based on the trend in changes.
5. Prediction of future land use pattern based on local scenarios.

Step 3- The third step is hydrologic modeling in changed scenarios. A hydrologic model should first be calibrated with the present data set. Then the same model may be used for future with the changed land use pattern and forecasted hydrometeorological variables (Fig. 7). All the scenarios as mentioned by IPCC should be considered and scenario uncertainty should be modeled. Finally the hydrologic scenario may be predicted in probabilistic framework.

Step 4- The final step is adaptation which includes vulnerability analysis, and analysis of risk which will be used for water resources planning and management in terms of reservoir operation, waste load allocation etc.

It should be noted that modelling land use change and incorporating them in the case study is a research challenge and potential research area. However, there is a need to focus more on land use change projections and consequences on hydrologic modelling for a reliable estimate. Considering both global and local changes for hydrologic projections can be considered as future research area.

\section{CONCLUDING REMARKS}

Impact of global climate change on hydrology and water resources needs to be assessed at river basin scales. The most credible tools of climate projections available today, viz., the GCMs. However, they provide the projections at much larger spatial scales. Downscaling of GCM projections of climate variables are therefore necessary. The paper discusses different downscaling techniques coupled with hydrologic models and their limitation. Guidelines for future research are also 
presented towards development of complete model for integrated catchment management in a changing world.

$\begin{array}{lll}\text { ABBREVIATIONS } \\ \text { GCM } & = & \text { General Circulation Model } \\ \text { IPCC } & = & \begin{array}{l}\text { Intergovernmental Panel on Climate } \\ \text { Change }\end{array} \\ \text { ENSO } & = & \text { El Nino Southern Oscillations } \\ \text { LAM } & = & \text { Limited Area Model } \\ \text { TAR } & = & \text { Third Assessment report } \\ \text { AR4 } & = & \text { Assessment Report } 4 \\ \text { SVM } & = & \text { Support Vector Machine }\end{array}$

\section{REFERENCES}

[1] Solomon SD, Qin M, Manning M, et al. The physical science basis, Contribution of Working Group I to the Fourth Assessment Report of the Intergovernmental Panel on Climate Change. Cambridge: Cambridge University Press UK 2007.

[2] Houghton JT, Ding Y, Griggs DJ, Noguer M, van der Linden PJ. The scientific basis, Contribution of Working Group I to the Third Assessment Report of the Intergovernmental Panel on Climate Change. Cambridge: Cambridge University Press UK 2001.

[3] Jones PD, JM Murphy, M Noguer. Simulation of climate change over Europe using a nested regional-climate model, I: assessment of control climate, including sensitivity to location of lateral boundaries, Q. J. R. Meteorological Society 1995; 121: 1413-9.

[4] Crane RG, Hewitson BC. Doubled $\mathrm{CO}_{2}$ precipitation changes for the susquehanna basin: down-scaling from the genesis general circulation model. Int J Climatol 1998; 18: 65-76.

[5] Wilby RL, Charles SP, Zorita E, Timbal B, Whetton P, Mearns LO. The guidelines for use of climate scenarios developed from statistical downscaling methods. Supporting material of the Intergovernmental Panel on Climate Change (IPCC), prepared on behalf of Task Group on Data and Scenario Support for Impacts and Climate Analysis (TGICA). (http://ipccddc.cru.uea.ac.uk/guidelines/StatDown_Guide.pdf). 2004.

[6] Hewitson BC, Crane RG. Large-scale atmospheric controls on local precipitation in tropical Mexico. Geophys Res Lett 1992; 19(18): 1835-8.
Wapnik VN. Statistical Learning Theory, New York: Wiley 1998.

[14] Nagesh Kumar D, K Srinivasa Raju and T. SathishRiver. Flow forecasting using recurrent neural networks, Water Resour Manage 2004; 18(2): 143-61.

[15] Tripathi S, Srinivas VV, Nanjundiah RS. Downscaling of precipitation for climate change scenarios: a support vector machine approach. J Hydrol 2006; 330: 621-40

[16] Govindaraju RS. Bayesian learning and relevance vector machines for hydrologic applications, In: $2^{\text {nd }}$ Indian International Conference on Artificial Intelligence (IICAI-05), Pune, India 2005.

[17] Ghosh S, Mujumdar PP. Statistical downscaling of GCM simulations to streamflow using relevance vector machine. Adv Water Res 2008; 31(1): 132-46

[18] Huth R. Sensitivity of local daily temperature change estimates to the selection of downscaling models and predictors. J Climate 2004; 17: 640-51.

[19] New M, Hulme M. Representing uncertainty in climate change scenarios: a Monte Carlo approach, Integrated assessment, vol. 1, no. 3, 2000.

[20] Gosain AK, Rao S, Basuray D. Climate change impact assessment on hydrology of Indian river basins. Curr Sci 2006; 90 (3): 346-53.

[21] Mujumdar PP, Ghosh S. Modeling GCM and scenario uncertainty using a possibilistic approach: Application to the Mahanadi River India, Water Resour Res 2008; 44: W06407.

[22] Ghosh S, Luniya V, Gupta A. Trend analysis of Indian summer monsoon rainfall at different spatial scales. Atmos Sci Lett 2009; 10 (4): 285-290.

[23] Ghosh S, Mujumdar PP. Climate Change Impact AssessmentUncertainty Modeling with Imprecise Probability. J Geophys Res Atmos 2009; 114: D18113.

(C) Ghosh and Misra; Licensee Bentham Open.

This is an open access article licensed under the terms of the Creative Commons Attribution Non-Commercial License (http://creativecommons.org/licenses/by-nc/3.0/) which permits unrestricted, non-commercial use, distribution and reproduction in any medium, provided the work is properly cited. 